\title{
LA LOCURA COMO VOZ DE LA DENUNCIA EN EL PABELLÓN NÚMERO SEIS, DE ANTÓN CHÉJOV ${ }^{1}$
}

\author{
Elsa Mariana del Castillo Pulgarín \\ Universidad Cooperativa de Colombia \\ marianadelcastillo@gmail.com
}

Recibido: 07/08/2020 - Aprobado: 02/09/2020 - Publicado: 15/04/2021

DOI: doi.org/10.17533/udea.lyl.n79a20

\begin{abstract}
Resumen: A lo largo de la historia, la locura, junto con el amor y la muerte, ha sido un tema frecuente en la literatura universal. Antón Chéjov (1860-1904), quien a través de sus cuentos se destaca por indagar no en el héroe noble de capacidades fantásticas, sino en el hombre mediocre e infeliz, emplea la locura como metáfora a partir de un enfoque realista para hacer una denuncia de las precarias condiciones hospitalarias y la indolencia de la sociedad rusa zarista de finales del siglo XIX, de la que se dice podría compararse con un pabellón de un hospital mental.
\end{abstract}

Palabras clave: literatura rusa; locura y literatura; El pabellón número seis (1892); Antón Chéjov (1860-1904); denuncia.

\section{INSANITY AS A VOICE OF DENOUNCEMENT IN WARD No. 6, BY ANTON CHEKHOV}

\begin{abstract}
Throughout history, insanity has been a recurring theme, along with love and death, in universal literature. Anton Chekhov (1860-1904), who through his stories has been distinguished for looking not into the noble hero with fantastic abilities, but into the mediocre and unhappy man, uses madness as a metaphor from a realistic approach to denounce the precarious hospital conditions of the tsarist Russian society at the end of the 19th century, which it is said could be compared to a ward in a mental institution.
\end{abstract}

Key words: Russian literature; insanity and literature; Ward No. 6 (1892), Anton Chekhov (1860-1904); denouncement.

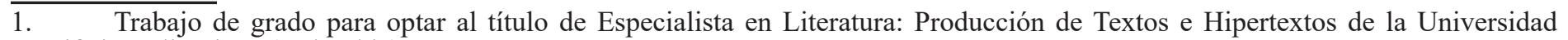
Pontificia Bolivariana (Colombia).
} 
A la memoria de María Basilisa Marulanda Ramírez.

Enero 29

Callando digo

Hoy nació Antón Chejov, en 1860.

Escribió como diciendo nada.

$Y$ dijo todo.

Eduardo Galeano, Los hijos de los días (p. 43).

\section{Introducción}

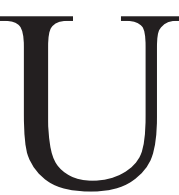

na de las numerosas posibilidades que ofrece la literatura, además de sumergir a los lectores en múltiples universos, es la de dar cuenta de un contexto histórico y cultural, que les permitan establecer un diálogo entre el individuo y su entorno. Las obras literarias pueden así considerarse como una suerte de documento histórico que da testimonio de las representaciones sociales en un período determinado.

El presente texto pretende realizar una exploración del concepto de locura como metáfora o metonimia en el cuento del escritor y dramaturgo ruso Antón Chéjov (1860-1904) llamado El pabellón número seis (1892), también conocido como La sala número seis, en el que dicho concepto, el de pabellón número seis, puede interpretarse como la alegoría de una sociedad en crisis: la de la Rusia zarista de finales del siglo xIx. Chéjov, considerado como uno de los maestros del relato corto y un gran exponente del realismo ruso, estimula a través de su cuento reflexiones filosóficas y sociales que le dan un valor profundo a su obra. Se abordará, pues, el tema en relación a la propuesta del pensador francés Michel Foucault (1976), quien hizo una revisión de la enfermedad y de la locura en el pasado clásico europeo y que, además, estudió las estructuras de poder en las instituciones que regulan el significado de lo que es o no es normal.

A partir de estos conceptos, se realizará un acercamiento al significado del término «locura», desde el psicoanálisis y la historia, en especial la de finales del siglo XIx, época en la que fue escrita la obra. Posteriormente se hará una revisión de la función de la locura en la literatura como símbolo, figura altamente trabajada en los estudios literarios, y finalmente se observará cómo se desarrolla a través de los personajes en El pabellón número seis.

\section{2. ¿Qué se entiende por locura?}

Aproximarse a la definición exacta de este término es una tarea compleja, ya que la locura es un concepto 
La locura como voz de la denuncia en El pabellón número seis, de Antón Chéjov

polisémico cuya definición depende de la época y del sistema de referencia que la enuncie. Sin embargo, si se retoma la analogía con el concepto de «mentira» y cómo esta se define a partir de lo que se considera como «verdad», la locura debe analizarse desde lo que se entiende por «cordura», es decir, como la falta de sensatez o de razón. Otra definición es la del médico y teólogo alemán Heinroth, citado por Foucault (1976), quien definió la locura como «[...] una manifestación, en el hombre, de un elemento oscuro y acuático, sombrío desorden, caos en movimiento, germen y muerte de todas las cosas, que se opone a la estabilidad luminosa y adulta del espíritu» (p. 28).

Desde un punto de vista científico, a partir de la investigación que hace el psiquiatra, historiador y filósofo peruano Germán E. Berrios (2008) en su libro Historia de los síntomas de los trastornos mentales, en el que describe la psicopatología descriptiva del siglo XIX, se tiene que:

Históricamente, el concepto de «delirio» se entremezcla con el de «locura» y depende de las teorías de pensamiento y credo contemporáneas. En Europa y hasta la década de 1850, délire y Wahn se referían tanto a la insania como al delirio (el término francés llamado también «delírium orgánico») Desde el siglo XVI, la palabra inglesa delusion ha significado «falsa opinión o creencia fija en relación con cosas objetivas» (OED, segunda edición). Esta definición intelectualista, aunque más limitada, es más fácil de explorar que sus equivalentes en la Europa continental (p. 214).

Puede decirse que no existe una definición única y absoluta de la locura, aparte de la definición popular que cada uno pudiese enunciar según el contexto individual en el que vive; cada definición varía entre el comportamiento que se priva del juicio, la conducta excéntrica o la ausencia de razón. En todo caso, la locura, diagnosticada o no, ha servido como vehículo para criticar, para explotar la relación del ser interior con el mundo, para desahogar las emociones, para explorar universos nuevos y exteriorizar lo que en verdad se quiere decir cuando la sociedad en la que se vive priva al sujeto de su humanidad. Es por ello que grandes autores se han valido de la figura del loco para exponer sus pensamientos $y$, de acuerdo con el impacto que han causado estas divulgaciones, las instituciones han determinado si es conveniente denominarlos locos o deshacerse de ellos y encerrarlos en el manicomio de los olvidados, de los que «no existen».

\section{La locura y la literatura}

La locura, junto con el amor y la muerte, es uno de los temas más recurrentes en la literatura universal, ya que es otra de las «conductas insensatas» inherentes al ser humano.

La locura y los personajes que la encarnan son descritos como aquellos que se salen del «modelo de cordura», el cual está determinado por los paradigmas sociales de cada época. Para indagar un poco más sobre este concepto, que ha sido tan diverso y polémico para algunos, se menciona a Foucault (1976), quien consideró que la locura es una temática digna de estudio y realizó una investigación sobre la experiencia de la misma, desde el Renacimiento hasta la Modernidad, en la que la figura del «loco» pasa de ser inicialmente aceptada en la sociedad para convertirse en una anomalía peligrosa que, por tanto, se procede a excluir y encerrar. El autor partió desde la Edad Media, en la que se inició la primera segregación importante de los enfermos, grupo mayoritariamente constituido por 
La locura como voz de la denuncia en El pabellón número seis, de Antón Chéjov

los leprosos, luego por los que padecieron enfermedades venéreas y finalmente por los que sufrían de trastornos mentales.

Más que hacer una teorización psiquiátrica sobre la locura, Foucault (1976i) señaló que «el loco» deja de ser personaje para convertirse, en el imaginario colectivo y a través del tiempo, en la personificación de la voz de la verdad:

La denuncia de la locura llega a ser la forma general de la crítica. En las farsas y soties, el personaje del loco, del necio, del bobo, adquiere mucha importancia. No está ya simplemente al margen, silueta ridícula y familiar: ocupa el centro del teatro como poseedor de la verdad [...]. Si la locura arrastra a los hombres a una ceguera que los pierde, el loco, al contrario, recuerda a cada uno su verdad. (p. 29).

Este fenómeno se evidencia en las artes escénicas y literarias precisamente porque estas parten de un componente cotidiano y universal. En la literatura, la figura del loco tiene su actuación protagónica en la medida en que cuestiona los comportamientos de la época en la que vive. Este es el caso del famoso Elogio de la locura de (1511) Erasmo de Rotterdam, en el que una voz hace una crítica severa de los paradigmas y dogmas del siglo XVI, que dan cuenta de una sociedad tradicionalista, tanto en el campo religioso como en el académico. Esa voz es precisamente la locura personificada, quien desde su perspectiva de narradora omnisciente dice las «verdades» sin tacto alguno y con tono de burla, al tiempo que reprocha la insensatez de aquellos que se autoproclaman cuerdos.

Incluso, previamente, en el año 1492, el poema satírico del Renacimiento escrito por Sebastián Brant titulado La nave de los locos y representado en la pintura por El Bosco, expone la locura del mundo contemporáneo de su época con el sarcasmo, la burla y el cuestionamiento a través de una compilación de viajes (Blake, 2009). Se trata de un barco en el que las personas que fueron expulsadas de las ciudades por «locos» son transportadas para finalmente ser abandonadas a la deriva en el agua. Cada uno de los tripulantes personifica uno de los vicios de la sociedad, recurso que le servirá a Brant para hacer sus denuncias sociales. En su artículo «Locura y literatura, la otra mirada» (2009), Elvira Sánchez Blake explica este fenómeno:

Locura y literatura son dos temas que aparecen intrínsecamente unidos ya sea por esa frontera liminal que existe entre el genio y la insensatez o quizá por la necesidad de poner en boca de personajes locos una verdad peligrosa. La figura del loco se ha convertido en un símbolo, analogía o parábola que significa un mundo en crisis y, en ocasiones, el espejo y catalizador de la conciencia crítica de la humanidad (p. 15).

Se puede identificar la locura como una temática llamativa, porque ella en sí misma guarda secretos indescifrables incluso para el propio ser humano: es una lucha constante consigo mismo, con su naturaleza, con su verdad y, quizá, la de otros. La locura rompe con lo cotidiano, con lo «normal». Según Foucault (1976), una de las características de la fascinación por la locura es que «las imágenes fantásticas que hace nacer no son de la superficie de las cosas.» (p. 41).

Aun cuando no es obligatorio pensar que para escribir bien la musa de la locura debe posarse la noche anterior sobre la cabecera de la cama del escritor, es cierto que se percibe una sensibilidad especial en los llamados locos, sensibilidad que trasgrede los límites de lo que es considerado como normal. Sánchez (2009) lo explicó en estas palabras: 
[...] la locura ocupa un espacio central y tiene como objetivo presentar una realidad desde una óptica diferente. Se establece así una correlación entre locura, mirada y literatura, como si la locura fuera el resultado de aprehender realidades desde una mirada alternativa para transmitir un mensaje que cuestiona o redefine una realidad. (p. 15).

Ahora bien, para volver a la investigación de Foucault, este hace una distinción de las representaciones de la locura que encuentra en las obras literarias de los siglos XVI y XVII, en especial en las de Cervantes y Shakespeare, que bien pueden aplicarse para el siglo XVIII. En el Quijote, por ejemplo, Foucault menciona una locura por identificación novelesca, la cual se refiere a la fantasía que se convierte en fantasma y, en general, a las novelas de imaginación en las que, por debajo, existe una relación entre la realidad y la imaginación, y una comunicación entre la invención y el delirio. Posteriormente, Foucault (1976) encuentra un personaje que a través de su imaginación se atribuye todas las cualidades o poderes de las que está desprovisto y lo llama la locura de la vana presunción; luego halla la locura del justo castigo que, como su nombre lo indica, ajusticia a través de los trastornos del espíritu y que a través del castigo revela la verdad; y, finalmente, habla de la locura titulada la pasión desesperada, cuando el amor engañado, sobre todo por la fatalidad de la muerte, no tiene otra salida que la demencia.

Si bien estos no son parámetros clasificatorios empleados actualmente, puesto que no existe ni siquiera un género literario llamado «literatura de la locura» o «literatura para locos» —es pertinente recordar que todos estamos locos, según el filósofo Blaise Pascal (1999, s. p.)—, esta clasificación foucaultiana proporciona un acercamiento a la función de la locura en los textos de dicha época, los cuales muestran una locura surgida a partir de eventos trágicos. Esta situación cambiaría pronto, a mediados del siglo XVII, cuando la locura abandona las historias al estilo cervantino y shakesperiano y «permite la manifestación de la verdad y el regreso apacible de la razón» (Foucault, 1976, p. 68). Es decir, ya la locura no es un castigo, sino que permite ver cuáles son los verdaderos problemas a lo largo de la trama.

Posteriormente, el concepto de la locura se transforma. Ya no es aquel ser aterrador de La nave de los locos sino que se vuelve más familiar, trayendo consigo la nueva institución del hospital de locos, en el que las diversas formas de locura encontrarán su lugar, con las características que siempre se han tenido en el imaginario colectivo: «[...]la locura frenética y necia, los sombríos melancólicos que recorren el campo, los locos borrachos, los desprovistos de memoria y entendimiento, los locos adormecidos y medio muertos, los locos atolondrados y con la cabeza vacía» (Foucault, 1976, p. 72). Este fenómeno será denunciado igualmente por los escritores que alguna vez fueron señalados como locos, como es el caso del poeta y dramaturgo francés Antonin Artaud (1990), que mencionó: «Así es como la sociedad mandó estrangular en su manicomio a todos aquellos de quienes quería desembarazarse o defenderse, porque habían rechazado convertirse en cómplices de algunas inmensas porquerías» (p. 54).

En el contexto latinoamericano, a lo largo de las últimas décadas, han sido numerosos los estudios que se han encargado de indagar sobre las relaciones entre literatura y locura, sus significados y representaciones en el contexto en el cual son escritas las obras. Una de estas aproximaciones es la que hace Andrea Kottow, en Historias de locuras en la literatura chilena del siglo XIX, o la modernidad y sus vicisitudes (2014), obra en la que se reflexiona sobre el papel de la locura como modelo de disidencia que cuestiona los proyectos de modernidad: 
La locura del personaje, entonces, ocuparía el lugar de un quiebre de la razón nacional que, a su vez, debe ser puesto en relación con una problemática asunción de los principios modernos, tan caros a la elite ilustrada del diecinueve. La modernidad aparece bajo esta perspectiva en tanto experiencia contradictoria, o incluso como una experiencia de lo contradictorio, manifiesta, a su vez, en una literatura comprendida como continente de sus contradicciones, evidenciadas en forma acentuada en un espacio periférico a la promulgación de las premisas modernas y a las realidades materiales que las sustentan. (s. p.).

La locura es sin duda un elemento presente en el ingenio humano, y el loco aparece ya sea como protagonista en una obra literaria que expone aquellas ideas oscuras que aturden al ser humano, o como espíritu inspirador de la mano que escribe. La categorización o medida de la ausencia de razón depende de cuantiosos puntos de referencia, que por su subjetividad realmente no importan. La locura simplemente revela el conjunto de miedos y obsesiones que hacen parte de la condición humana.

Después de este breve acercamiento a la locura en la literatura, se hará una descripción de El pabellón número seis, relato de Antón Chéjov, y su enfoque de la locura.

\section{Chéjov y el pabellón número 6}

Uno de los numerosos ejemplos de obras literarias que retoman el papel del loco en el sentido de outsider o paria que expresa pensamientos diferentes que trasgreden los paradigmas sociales se puede encontrar en $\mathrm{El}$ pabellón número 6 de Antón Chéjov, cuento escrito en 1892, que describe con acierto los escenarios sociales de la Rusia zarista de finales de siglo xix, período de atrasos tecnológicos, escasas reformas, altas condiciones de pobreza y miseria. Su retrato de una población sin aspiraciones, las amplias descripciones de los paisajes y de los rasgos físicos del entorno, pero sobre todo la exploración psicológica de los personajes, hacen del cuento un fiel exponente del realismo literario ruso y de Chéjov uno de los mejores exponentes del relato corto.

El profesor mexicano Óscar Uribe Villegas (1974) habló sobre la imagen que se presenta del hombre en sociedad en la cuentística rusa:

De una manera burda, puede decirse que estos cuentos reflejan [...] la relación entre las autoridades y la población gobernada; las relaciones interétnicas en la Rusia zarista; la vida de los siervos y el pisoteo de su dignidad; el desempeño estacional de un trabajo citadino por los rurícolas; el choque de la benevolencia idealista hacia las otras clases con condiciones estructurales objetivas de la sociedad; la hipocresía y la ineficacia administrativa del régimen zarista; [...] la actitud de hombres de diferentes edades y posiciones, frente a la muerte; la vida de los deportados y vagabundos; las miserias de los sirgadores y su explotación por la vanguardia capitalista del Imperio Ruso; la vida de un hombre de ciencia en la Rusia de los zares; la autenticidad del sentimiento religioso y sus repercusiones sociopolíticas (p. 343).

Chéjov se caracteriza por abordar precisamente temáticas cotidianas que, en realidad, y de manera no muy sutil, exteriorizan problemáticas internas y desgracias del ser humano, es decir, lo expone desde lo más interno de sí mismo y lo ubica en sociedades modernas hostiles, aspecto característico del período histórico y de la vida misma.

Además, Chéjov denuncia por medio de personajes aparentemente triviales y mezquinos la mediocridad del 
La locura como voz de la denuncia en El pabellón número seis, de Antón Chéjov

hombre. En vez de héroes colmados de talento y honestidad absoluta, presenta protagonistas estereotípicamente antiheróicos, así como lo expresó Jorge Bustamante (2008): «Chéjov detiene su mirada inquieta en los hombres casuales y ordinarios, en las situaciones más fortuitas» (p. 68). De igual manera, Máximo Gorki (1994), en sus anotaciones personales y biográficas del escritor, reveló que:

[...] nadie mejor que él, ha comprendido con tanta claridad y fineza lo trágico en las futilezas de la vida, nadie, antes que él, supo mostrarle al hombre con despiadadas verdades, el fastidioso y miserable cuadro de su vida, tal como se desarrolla en el oscuro caos de la mediocridad burguesa (p. 49).

Pues bien, Chéjov, desde una perspectiva omnisciente que interactúa con el lector en una voz narrativa jovial, cuenta la historia de un hospital general y de un pabellón en especial, el de los locos y sus cinco habitantes. Comienza por Nikita, el guardián, un viejo soldado de carácter violento que golpea con crueldad a los pacientes y justifica sus acciones aduciendo que son para establecer el orden. Luego, los locos: un pelirrojo que se lamenta día y noche, un judío llamado Moseika que pierde la cordura cuando se incendia su negocio de sombreros y que se caracteriza por pedir limosna en las calles — es al único que dejan salir —, un muzhik — campesino— gordo y sucio que ha perdido la facultad de pensar y de sentir, un clasificador de correos obsesionado con las condecoraciones y, finalmente, Iván Dmítrich Grómov en el que se diagnostica un trastorno de delirio de persecución.

Es pertinente detenerse un poco en Iván, el protagonista del cuento, para resaltar que antes de su enfermedad y de ser internado había sido un hombre instruido que leía mucho, un ujier y un secretario de provincias. Su locura comienza después de un encuentro con presos, con el que surge su delirio de persecución al pensar que en cualquier momento él mismo podría ser arrestado. Se imagina variados malentendidos por los que podría ser llevado injustamente a la cárcel, por lo que su cerebro nunca descansa. Se caracteriza, además, por su desprecio a los habitantes de su pueblo, que tilda de ignorantes y se muestra como un personaje que habla siempre con honestidad, idea sustentada por el testimonio de sus vecinos y por los que lo conocieron en salud. Inicialmente lo ingresan en el pabellón de enfermedades venéreas del hospital, pero por orden del doctor Andréi Yefímych Raguin, el segundo protagonista, es enviado al pabellón número 6.

En este apartado conviene retomar lo que en la medicina se consideraban como características de la locura o del delirio en la mitad del siglo XIX, con las cuales se puede intuir que Iván Dmítrich Grómov fue diagnosticado para recibir su «sentencia». Según la psiquiatría francesa, «otros aspectos clínicos del delírium histérico incluían: exaltación de la inteligencia, fuga de ideas, ideas fijas, automatismos y conducta erótica» (Berríos, 2008, p. 265) El uso idiosincrásico y general de délire refleja que el concepto en sí seguiría siendo confuso hasta finales del siglo. (Berríos, 2008).

Andréi Yefímych, el doctor, es el personaje que personifica la mediocridad en la historia. Desde el principio se revela que él mismo reconocía que nunca había tenido vocación por la medicina ni por las ciencias en general, debido a que quería dedicarse al sacerdocio — se considera a sí mismo extremadamente piadoso-, pero no lo hizo por mandato de su padre. Su personalidad indolente se refleja en la caracterización de su aspecto exterior, que da cuenta del poco cuidado que tiene de sí mismo. Su temor a la confrontación y su falta de carácter se evidencian 
La locura como voz de la denuncia en El pabellón número seis, de Antón Chéjov

en el trato con los otros, cuando llega a hacerse cargo del hospital y lo determina como un «...centro inmoral y pernicioso en grado sumo para la salud de sus pacientes» (Chéjov, 2010, p. 198), hecho que ignora sin siquiera pensar en proponer un cambio en dicha situación. Su personalidad es sumisa, nunca insiste, ni ordena, ni prohíbe; básicamente no ejerce sus responsabilidades y adopta una actitud indiferente frente a la problemática social que lo rodea.

Con el pasar de los años, el trabajo del doctor se convierte en algo tan monótono que incluso repite las mismas preguntas a sus pacientes y les receta cualquier medicamento. Excusa su comportamiento con reflexiones baratas, como la de que finalmente todos vamos a morir de una cosa u otra algún día. Sin embargo, existe un moderado remordimiento consciente en sí mismo, ya que reconoce que no es un hombre honrado: él sabe que engaña a la gente, pero se disculpa diciendo que no es él el verdadero culpable, sino la época a la que pertenece. Irónicamente, este hombre siente un amor profundo por la inteligencia y se muestra también como un lector dedicado que se detiene en sus lecturas — en contraposición a Iván, que lee muy rápido- . Es un personaje que hace todos los días lo mismo y conversa constantemente con su único amigo, Mijail Averiánych. Su único deseo sincero es encontrar personas y conversaciones inteligentes, porque asegura que no hay nadie para sostenerlas.

Vale la pena mencionar lo curioso de esta caracterización de Andréi Yefímych por parte de Chéjov, ya que un médico mediocre que sienta esa pasión por la lectura y por la inteligencia es un fenómeno relativamente contradictorio, como sucede en la vida misma. Sin embargo, ese fervor por la inteligencia que muestra el doctor, es una característica que precisamente es visualizada en las propias palabras de otro escritor ruso anteriormente mencionado, Máximo Gorki (1994):

En otra ocasión, sentado cerca de una ventana abierta y mirando a lo lejos el mar, exclamó con inesperada irritación: Estamos acostumbrados a vivir en la esperanza del buen tiempo, de una hermosa cosecha, de una agradable aventura, de enriquecernos o de ser nombrados prefecto de policía. Pero la esperanza de hacerse más inteligente, no la percibo entre los hombres. Nos decimos que con otro zar las cosas mejorarán, y que en doscientos años más serán aún mejores, pero nadie hace porque la mejoría llegue mañana... (p. 57).

Chéjov destaca en el carácter de Andréi Yefímych lo que es, sin duda, falta de vocación. Aunque puede verse un mínimo interés de actualización en el área de la medicina, este personaje no relaciona el intelecto con su rol actual. Además, prefiere ignorar las condiciones poco sanitarias y los maltratos a los que están sometidos los enfermos en el hospital con el fin de no tener preocupaciones o tareas profesionales extra que alteren su confort. «Desde la óptica psicodinámica, el doctor Yefímych se sirve del mecanismo defensivo de racionalización, consistente en una justificación aparentemente lógica y justa, pero errónea, con la que alivia o evita ansiedad, sentimientos de culpa, etcétera» (Martínez, Pérez, 2012, p. 1561).

Si se observa detenidamente la situación del hospital y del pabellón número seis, se hace interesante que se albergue tan precariamente a los locos sin ningún tipo de distinción entre patologías, tal como Foucault describió la situación en la Edad Media. El doctor incurre, pues, en esta clasificación negligente, aun cuando lee maravillado sobre los avances de la medicina.

Por otro lado, sabe perfectamente que en estos veinticinco últimos años se han dado unos cambios asombrosos en 
medicina [...]. La psiquiatría, con su clasificación actual de las enfermedades, con los métodos de diagnóstico y tratamiento: todo, comparado con lo que había, es un mundo nuevo (Chéjov, 2010, p. 208).

Es pertinente anotar que Chéjov fue médico de profesión y sufrió de tuberculosis, por lo que conocía muy bien las formas de aislamiento y tratamiento de los enfermos, además de la burocracia administrativa hospitalaria. En el relato da cuenta de una sociedad en vía de desarrollo voluntariamente ignorada por el personal de este hospital, debido a la falta de «solidaridad» del doctor previamente mencionado. Si se hace un rastreo de la historia del psicoanálisis, específicamente en la Rusia de este período, se encuentra que:

[...] hubo que esperar hasta la mitad del siglo XVIII para que se publicaran trabajos psiquiátricos genuinamente rusos, así como para que se abrieran los primeros centros para enajenados mentales en Novgórod, Moscú y San Petersburgo, a los que se conocían popularmente como casas amarillas, dado el color de la pintura de sus fachadas, entonces la más barata del mercado, bajo cuyo techo convivían pacientes afectos de muy diferentes cuadros clínicos, que etiológicamente solía atribuirse a lo que entonces se denominaba degeneración moral (Balbuena, Francisco \& Sánchez-Barranco, 2004, p. 146).

Es indispensable mencionar a un nuevo personaje, precisamente porque hace parte del conjunto de individuos deshonestos. Se trata de Yevgueni Fiódorych Jóbotov, otro médico encargado de ayudar a Andréi Yefímych de vez en cuando. También él se encuentra «indignado» por la falta de asepsia del hospital, pero no hace nada por mejorar las condiciones, ni siquiera por enunciarlas, con la excusa de no querer herir al doctor. Su objetivo es deshacerse de él para posicionarse en su cargo. Es un personaje que reitera la mediocridad y falta de empatía con los enfermos.

Así, pues, en el pabellón número seis los doctores son deshonestos, y Andréi Yefímych lo sabe. No obstante, su carácter indolente le impide emprender acción, incluso cuando tiene la facultad y el poder para hacerlo.

\section{La locura y la razón conversan}

Un día cualquiera el doctor Andréi Yefímych tiene la oportunidad de conocer a Iván y queda totalmente impresionado por su inteligencia en la conversación, así que comienza a visitar el pabellón todos los días para escucharlo. En este encuentro, en el que departirán por horas, Iván da cuenta de su lucidez —a pesar de su diagnóstico de delirio de persecución - y no tarda en hacer una crítica social directa de la ignorancia y la hipocresía de la sociedad e incluso del doctor mismo, a lo que este, extrañamente, responde con agrado, al ver en Iván una persona que piensa y reflexiona. Iván se queja con el doctor de su estado y el de sus compañeros de manera inmediata, y revela los abusos de los que han sido víctimas:

Sí, estoy enfermo. Aunque también decenas, centenares de locos andan por ahí en libertad, porque su ignorancia es incapaz de distinguirlos de los sanos [...] ¿por qué pues estos desgraciados y yo debemos estar aquí por todos los demás, cómo chivos expiatorios? Usted, el practicante, el celador y toda su gentuza hospitalaria son incomparablemente inferiores en lo moral a cualquiera de nosotros. ¿Por qué somos nosotros los encerrados y no usted? ¿Dónde está la lógica? - La moral y la lógica (responde el doctor) no tienen nada que ver en esto. Todo depende de las circunstancias (Chéjov, 2010, p. 211). 
Se puede relacionar este apartado con la posición teórica de Foucault, en la que se ponen en discusión las fronteras de la normalidad y anormalidad y el concepto de locura. También se puede equiparar con la opinión de otros escritores que, excluidos y diagnosticados como locos expresan denuncias en sus obras, como es el caso de Artaud en su escrito Van Gogh: el suicidado por la sociedad (1990): «[...]así es como una sociedad tarada inventó la psiquiatría, para defenderse de las investigaciones de algunas inteligencias extraordinariamente lúcidas, cuyas facultades de adivinación le molestaban» (p. 54). Triunfo Arciniegas (2002) sitúa esta discusión en la época contemporánea:

Locos, criminales, prostitutas, alcohólicos, ladrones, drogadictos, suicidas, poetas malditos, vagabundos y extravagantes de todo tipo rompen las normas sociales y deben aislarse. Se les designan territorios: calles, bares, prostíbulos. O se les amontona en el barco de los locos, para que deambulen por los mares más lejanos y nunca toquen a nuestra puerta ni se nos crucen en el camino. El hospicio alberga a los locos y sus demonios y la cárcel nos mantiene a salvo de los criminales, porque locura y criminalidad representan la parte del hombre que debe eliminarse o al menos esconderse, como la basura, debajo de la alfombra. El criminal debe expiar la ofensa y el loco debe pagar por su comportamiento. (p. 79).

Una reflexión similar será la respuesta del doctor a Iván, al mencionar que cuando la sociedad se protege de los criminales, de los enfermos psiquiátricos y, en general, de la gente incómoda, es invencible (Chéjov, 2010). Como regla, las sociedades humanas guardan las apariencias escondiendo aquello que las avergüenza.

Así pues, el doctor empieza a cuestionarse sobre ese sujeto que, diagnosticado como loco por la sociedad misma — mas no por profesionales médicos psiquiátricos_-, sabe razonar y argumentar. Después de tantos años de quejas de una sociedad aburrida y trivial, en la que no había con quién hablar o de quién escuchar algo interesante, el doctor encuentra en Iván a una persona con la que puede entablar conversaciones profundas y polémicas, por lo que empieza a visitarlo con frecuencia. El loco razonante es por eso una figura muy trabajada en la filosofía, en la historia y en los estudios literarios.

El discurso literario de la decadencia no tardó en apropiarse y ahondar en el ideal del genio enfermo, convirtiéndolo en motivo privilegiado de su catálogo temático. El artista enfermo, por un lado, y la infinita melancolía, convertida en auténtico mal del siglo, resultaron la perfecta imagen para mostrar tanto el rechazo al optimismo racionalista y la idea positivista de fe en el progreso como el desafío a un sistema de valores burgués y utilitarista (Clúa Ginés, 2009, p. 40).

Iván, en su delirio, acusa al doctor inicialmente de ser un espía y un «sonsacador». El doctor, de manera cínica, le dice que, incluso si sus afirmaciones fueran reales, no estaría en mejores condiciones, puesto que en la cárcel o en cualquier otro lugar tendría una suerte aún peor. El doctor pretende darle consuelo, aconsejándole que busque la paz en su interior. Añade que las personas inteligentes no se quejan y desprecian el sufrimiento, y afirma que es posible controlar el dolor, pues el sabio está siempre satisfecho y no se asombra ante nada. El doctor finaliza diciendo que aquello que lo perturba realmente es algo insignificante y que solo debe preocuparse por comprender la vida y buscar la felicidad.

Iván, con gran euforia y argumentos precisos, da a conocer su opinión y le hace saber al doctor que es un ignorante, un mediocre y un perezoso que precisamente ignora el sufrimiento ajeno: 
¡Yo reacciono! Ante el dolor respondo con gritos y lágrimas; ante la ruindad con la indignación, y la ignominia me produce asco. En mi opinión, es propiamente esto lo que se llama vida. Cuanto más inferior es el organismo, menos sensible se muestra y más débilmente responde a un estímulo, y cuanto más superior, con mayor sensibilidad y energía reacciona ante la realidad [...] Los estoicos a los que usted quiere parodiar, eran unos hombres extraordinarios, pero sus enseñanzas se detuvieron hace dos mil años y no han avanzado un palmo ni lo avanzarán. ¿Por qué? Pues porque no son prácticas ni aptas para la vida. Solo tuvieron éxito entre una minoría, que pasaba su vida en el estudio, deleitándose con todo tipo de teorías, pero la mayoría de la gente no las entendía. Una doctrina que predica la indiferencia hacia las riquezas y las comodidades de la vida, el desprecio al sufrimiento y a la muerte, es del todo incomprensible para la inmensa mayoría, porque esta mayoría nunca ha conocido ni la riqueza ni las comodidades de la vida; y despreciar los sufrimientos significaría para ellos despreciar su propia vida, ya que toda la esencia del hombre está formada por las sensaciones de hambre, de frío, por ofensas, pérdidas y miedo... (Chéjov, 2010, p. 218).

Existe una estrecha relación entre lo que piensa Iván, el internado del pabellón número seis, y lo que expresa libremente el personaje de la obra de Erasmo de Róterdam (2010). Ese personaje, la locura, tiene mucho que decir sobre los estoicos, definidos por ella misma como aquellos señores que se dejan barba de chivo «como señal de sabiduría» (p. 20), que piensan que su atención debe estar dirigida exclusivamente a la razón y a la virtud, y que consideran que las pasiones y demás nimiedades corresponden a individuos indignos y arrastrados por la estupidez. Los estoicos son aquellos que «apartan indudablemente todas las emociones del hombre sabio, como si fuesen enfermedades» (p. 37), y niegan su propia condición de seres humanos, así como el gozo de lo insulso.

Gracias a estas reflexiones y atraído por las conversaciones inteligentes con Iván, el doctor continúa visitándolo con frecuencia, lo cual no es bien visto por su colega y supuesto amigo Jóbotov y por los otros internos del hospital. Con prontitud comienzan las habladurías y rumores que sugieren comportamientos anormales de este, situación que el oportunista Jóbotov no deja pasar para adueñarse de su cargo y deshacerse del doctor.

En primera instancia, las personas cercanas invitan al doctor Andréi Yefímych a un «descanso». Él acepta a regañadientes, y viaja con aquel amigo de hacía muchos años, Mijaíl Averiánych, el cual mantiene un comportamiento grosero y ridículo con la servidumbre durante toda la travesía. El doctor detecta características de este que antes no le molestaban y hace una interesante reflexión: se pregunta cuál de los dos está loco, si él, que sostiene conversaciones sensatas con un enfermo mental, o ese ser gritón e inculto, que además perdió su dinero en el juego y pretende obligarlo a hacer cosas que no desea.

Sin embargo, con el pasar de los días, el doctor olvida temporalmente a Iván, pierde el interés en la lectura y hasta se agota con tan siquiera intentarlo. Yefímych pasa por un proceso de decadencia, desmotivado por la sociedad en la que él mismo participa, y abandona poco a poco su rutina diaria. Así lo expresa a su amigo:

Mi enfermedad consiste solo en que a lo largo de veinte años, en toda la ciudad solo he encontrado a una persona inteligente y resulta que además es un loco [...] no hay enfermedad alguna, solo he caído en el círculo vicioso del cual no hay salida. Ya todo me da igual, estoy dispuesto a todo. (Chéjov, 2010, p. 238).

En su desesperanza, Andréi Yefímych tiene un episodio de ira frente al doctor Jóbotov y su amigo Mijaíl, momento aprovechado para engañarlo,diagnosticarlo definitivamente como loco, y recluirlo en el pabellón número seis, bajo las mismas condiciones que él mismo había querido ignorar desde su llegada. No se revela un arrepentimiento directo en el doctor, aun cuando vive en carne propia los maltratos que sufrían sus pacientes por 


\section{La locura como voz de la denuncia en El pabellón número seis, de Antón Chéjov}

su mano, y aunque sí reflexiona sobre estos sucesos, no cambia su conducta y encuentra excusas y justificaciones:

¿Cómo había podido suceder que durante más de veinte años él no supiera o no quisiera saber todo aquello? No conocía, no tenía idea de lo que era el dolor, o sea que no era culpable, pero su conciencia, tan implacable y brutal como Nikita, lo dejó helado de la cabeza a los pies. (Chéjov, 2010, p. 245).

A pesar de todo, el doctor acepta su condición de hombre débil y mezquino, de hombre indiferente que, aunque se denominaba a sí mismo como un ser que pensaba bien y con sensatez, ha sido derrotado por la brutalidad de la vida. (Chéjov, 2010, p. 243).

El doctor es tomado por loco y encerrado, no por un diagnóstico médico real, sino más bien social, como le había pasado con anterioridad a Iván. Esta situación es totalmente contradictoria con las prácticas científicas que comenzaban a desarrollarse en la época:

La rápida evolución de la psiquiatría en los siglos XIX y Xx ha transformado profundamente el significado del término «locura», que hoy en día solo se utiliza en el habla popular. La clínica médica lo ha sustituido por los términos «neurosis», «psicosis», «melancolía», o «depresión» (Brenot, 1998, p. 32).

El doctor, indignado ante su nueva situación, reacciona contra los eventos adversos que le están sucediendo y se convierte en un loco que denuncia y se rebela, pero precisamente por esta razón es injustamente encerrado. El doctor se convierte en víctima de aquello que se negó a combatir cuando estuvo bajo su jurisdicción.

Posteriormente, el doctor Yefímych se reencuentra con Iván y se desahoga con él, a lo que este responde con sarcasmo y un aire victorioso: «ah vaya, ¡también le han metido aquí! [...] ¿No ha estado chupando la sangre de la gente? ¡Pues ahora se la van a chupar a usted! ¡Excelente!» (Chéjov, 2010, p. 241). La desesperación y el miedo se apoderarán del doctor, a lo que Iván le responde que: «filosofée un rato» (p. 241), haciendo alusión a las recomendaciones que el doctor le había hecho cuando se quejaba de su situación.

Andréi Yefímych querrá buscar ayuda e intentar aclarar las cosas, pero no lo dejarán salir y, en una disputa contra el celador Nikita, será brutalmente golpeado en la cabeza por su antiguo subordinado para finalmente morir al otro día, ser enterrado y despedido por unos pocos.

De esta manera, un hombre muere recluido en un pabellón de un hospital, como muchos mueren todos los días. No importan las palabras ni los juicios, el hombre común de Chéjov no nació para ser héroe ni para la gloria. Es posible cuestionarse también, al igual que el doctor, sobre quién es el que está realmente loco, si el recluido Iván que se queja con vehemencia de su situación y la de la sociedad, o el doctor que se cree sabio, pero es incapaz de subsanar las condiciones infrahumanas a las que están sometidos los pacientes del hospital y los enfermos en general, aun cuando cuenta con las herramientas para subsanar esta situación.

La literatura es pues una herramienta que puede servir para dar testimonio de cómo la sociedad, en algunas circunstancias, define el concepto de locura según los comportamientos que le sirven, y usa esa figura, la del loco, para decir lo que los «cuerdos» temen:

De la nave de los locos al sanatorio psiquiátrico, el razonamiento de la exclusión siempre es el mismo: está loco aquel que ofende las reglas de la moral, del bien pensar y de la sociedad. Contrariamente a lo habitual en el hospital 
La locura como voz de la denuncia en El pabellón número seis, de Antón Chéjov

general, donde la admisión requería siempre un diagnóstico médico, el ingreso en el hospital psiquiátrico parecía depender, hasta hace unos años, de un criterio más social que clínico, ya que se admitían en él, además de a los enfermos mentales, a todos aquellos delincuentes, alcohólicos, toxicómanos o vagabundos cuyo comportamiento perturbaba el orden social. (Brenot, 1998, p. 30).

Para terminar, se retoman los comentarios de Jorge Bustamante en sus Reflexiones sobre Chéjov (2008):

Las resonancias de los relatos chejovianos en sus lectores son misteriosas. Por un lado, pareciera que no sucede nada importante en sus historias; por el otro, al terminar de leer, las reverberaciones son tan intensas e intempestivas que uno siempre quisiera seguir leyendo más, para saber qué pasa, pero aparentemente no pasa mayor cosa. (p. 69).

Chéjov se vale de dos personajes aparentemente simples y ordinarios para evidenciar esa otra realidad de la que poco se habla porque es incómoda, toca la sensibilidad humana, y genera un malestar cuando se cierra el libro: la locura.

\section{Conclusiones}

El análisis realizado de la obra permite plantear que el poder simbólico de este relato reside en la percepción de Rusia como un pabellón de hospital con condiciones de salubridad reprochables que encierra y oprime la libertad de pensamiento, un pabellón en el que reside la corrupción, la deshonestidad, la falta de ética profesional y la indolencia, y en el que se percibe un sinsentido en la vida de sus personajes o habitantes.

En este cuento se abordan tanto las cuestiones sociales como el problema filosófico de la locura, la cual es utilizada como vehículo para denunciar la pésima realidad hospitalaria y social de la Rusia de finales del siglo XIX. Chéjov, como otros escritores en diferentes períodos, propone una mirada crítica a través de las vivencias de sus personajes, mirada que incita tanto a la reflexión como a la compasión. El autor plantea una discusión sobre el valor de la inteligencia cuando hay ausencia de empatía y cuando se permite que la mediocridad sea el lugar común para la toma de decisiones en instituciones tan importantes como los hospitales y los centros psiquiátricos.

Chéjov continúa problematizando el concepto de locura por medio de sus dos personajes, Iván el loco y Andréi Yefímych el doctor, quienes proponen reflexiones internas y diálogos que invitar a pensar si la sensatez o la inteligencia son conceptos que se oponen a la locura: ¿quién es realmente el loco?, ¿ellos o yo?

Podrán hacerse estudios posteriores que den a conocer diferentes análisis en relación con la locura descrita por los personajes de Chéjov en El pabellón número seis, los cuales pueden dilucidar diversas perspectivas en torno a la locura y su papel según los contextos socioculturales. 


\section{Referencias bibliográficas}

1. Arciniegas, T. (2002). Creatividad y locura. Hojas Universitarias, 5 75-79.

2. Artaud, A. (1947/1990). Van Gogh: el suicidado por la sociedad. Revista Prometeo, 19, 54-58.

3. Balbuena, F., Sánchez-Barranco, A. (2004). Breve historia del psicoanálisis en Rusia. Revista de la Asociación Española de Neuropsiquiatría, 90, 145-164. http://scielo.isciii.es/pdf/neuropsiq/n90/v24n2a10.pdf

3. Berrios, G., Historia de los síntomas de los trastornos mentales. La psicopatología descriptiva desde el siglo XIX (2008). México: Fondo de Cultura Económica.

3. Brenot, P. (1998). El genio y la locura. Barcelona: Ediciones Grupo Zeta.

4. Bustamante, J. (2008). Reflexiones sobre Chéjov - La ficción de la vida ínfima. Revista Universidad de Antioquia, 292, 63-70.

5. Chéjov, Á. (1982/2010). Cuentos imprescindibles. Bogotá: Editora Géminis Ltda.

6. Chesterton, G. K. (2012). Los libros y la locura. Revista Leer y Releer, 67, 5-10.

7. Clúa, I. (2009). La morbidez de los textos: literatura y enfermedad en el fin de siglo. Revista de Historia de la Psiquiatría, 9, 33-52.

8. Erasmo de Rotterdam (1509/2010). Elogio de la Locura. Bogotá: Libros Hidalgo.

9. Foucault, M. (1976). Historia de la locura en la época clásica I. México, D.F.: Fondo de Cultura Económica. 10. Gorki, M. (1994). A propósito de Antón Chéjov y su obra. En Chéjov. Á., Historia de un contrabajo (pp. 3-224). Bogotá: Editorial Norma.

11. Kottow, A. (2014). Historias de locuras en la literatura chilena del siglo XIX, o la modernidad y sus vicisitudes. https://journals.openedition.org/nuevomundo/66914

12. Martínez-Otero Pérez, V. (2012). Salud mental hospitalaria y comunitaria en el pabellón número 6, de Chéjov. Revista Electrónica de Psicología Iztacala, 15(4), 1548-1570.

13. Sánchez, E. (2009). Locura y literatura: La otra mirada. Revista La manzana de la discordia, 4(2), 15-23. Universidad del Valle.

14. Villegas, O. (1974). El hombre en sociedad en la cuentística rusa: De Pushkin a Chéjov. Revista Mexicana de Sociología, 36(2), 343-385. 